Article

\title{
Contrasting Views of Citizens' Assemblies: Stakeholder Perceptions of Public Deliberation on Climate Change
}

\author{
Rebecca Sandover $^{1, *}$, Alice Moseley ${ }^{2}$ and Patrick Devine-Wright ${ }^{1}$ \\ ${ }^{1}$ Department of Geography, University of Exeter, Exeter, EX4 4PY, UK; E-Mails: r.sandover@exeter.ac.uk (R.S.), \\ p.g.devine-wright@exeter.ac.uk (P.D.-W.) \\ 2 Department of Politics, University of Exeter, Exeter, EX4 4PY, UK; E-Mail: a.moseley@exeter.ac.uk \\ * Corresponding author
}

Submitted: 17 January 2021 | Accepted: 18 March 2021 | Published: 28 April 2021

\begin{abstract}
It has been argued that a 'new climate politics' has emerged in recent years, in the wake of global climate change protest movements. One part of the new climate politics entails experimentation with citizen-centric input into policy development, via mechanisms of deliberative democracy such as citizens' assemblies. Yet relatively little is known about the motivations and aspirations of those commissioning climate assemblies or about general public perceptions of these institutions. Addressing these issues is important for increasing understanding of what these deliberative mechanisms represent in the context of climate change, how legitimate, credible and useful they are perceived to be by those involved, and whether they represent a radical way of doing politics differently or a more incremental change. This article addresses these gaps by presenting findings from mixed method research on prior expectations of the Devon Climate Assembly, proposed following the declaration of a climate emergency in 2019. The research compares and contrasts the views of those commissioning and administering the citizens' assembly, with those of the wider public. Findings indicate widespread support, yet also considerable risk and uncertainty associated with holding the assembly. Enabling input into policy of a broad array of public voices was seen as necessary for effective climate response, yet there was scepticism about the practical challenges involved in ensuring citizen representation, and about whether politicians, and society more generally, would embrace the 'hard choices' required. The assembly was diversely represented as a means to unlock structural change, and as an instrumental tool to achieve behaviour change at scale. The Devon Climate Assembly appears to indicate 'cautious experimentation' where democratic innovation is widely embraced yet carefully constrained, offering only a modest example of a 'new climate politics,' with minimal challenges to the authority of existing institutions.
\end{abstract}

\section{Keywords}

citizens' assemblies; climate assembly; climate change; climate emergency; climate politics; deliberation; democratic innovations

Issue

This article is part of the issue "Is There a New Climate Politics? Emergency, Engagement and Justice" edited by Anna R. Davies (Trinity College Dublin, Ireland), Stephan Hügel (Trinity College Dublin, Ireland) and Vanesa Castán Broto (University of Sheffield, UK).

(C) 2021 by the authors; licensee Cogitatio (Lisbon, Portugal). This article is licensed under a Creative Commons Attribution 4.0 International License (CC BY).

\section{Introduction}

The necessity to rapidly and extensively respond to climate change has been repeatedly emphasised by scientific experts (e.g., Intergovernmental Panel on Climate Change, 2018). A narrative of Climate Emergency has emerged over recent years, driven by social movements such as Fridays for Future. Policy makers at different scales have responded through declarations of Climate Emergency and setting target dates to reach net zero emissions. At the time of writing, $74 \%$ of local authorities in the UK have declared a Climate Emergency, as 
has the UK national government (Climate Emergency UK, 2021). Civil society groups, notably Extinction Rebellion in the UK, have demanded greater public participation in climate policy making through the use of deliberative mechanisms such as citizens' assemblies with the ability to produce recommendations that are binding and not just advisory (Extinction Rebellion, 2019). Bryant and Stone (2020) identify six UK local authorities-all based in cities - that have implemented public deliberations on climate change. However, judging the extent to which these new narratives, declarations and deliberations are indicators of a 'new climate politics' is uncertain. In the case of public deliberations, it requires analysis of the motivations and rationales underlying why these new mechanisms are being introduced by policy makers-is the aim to re-configure power relations between citizens and elected representatives? Or to address particular challenges with representative politics (e.g., lack of trust, lack of citizen engagement, short-term interests), which may need addressing to respond to the climate crisis? Upon what criteria are the legitimacy and credibility of citizens' assemblies based? And what happens next: Do they lead to substantively new policies and actions on climate adaptation and mitigation? Are citizens' climate assemblies a one-off, or do they represent a more enduring shift towards public deliberation in policy making?

In this study, we begin to address these important questions through a case study of the first citizens' climate assembly to take place in a rural county of the UK, in Devon, South West of England (hereafter referred to as 'the Devon Climate Assembly'). Addressing gaps in the literature on citizens' assemblies, we focus on the views of stakeholders, including public officers (administrators and managers of local authorities and other public organisations), as well as members of the wider public who contributed to a public call for evidence as part of the wider process leading up to the assembly. With regards to temporality, we address the gap that little research has explored stakeholder perceptions of public deliberation before an assembly takes place. This is useful to reveal the expectations and anticipations associated with democratic innovations when citizens' assemblies are held in places for the first time: How are they justified by policy makers as a necessary departure from conventional politics? Upon what criteria are their legitimacy and credibility argued to lie?

Devon represents a suitable context to address these questions. In 2019, local councils across the county declared a Climate Emergency. Devon County Council convened a partnership of 27 organisations - the Devon Climate Emergency Response Group (hereafter DCERG) - to coordinate responses. A Net Zero Task Force made up of 15 experts was set up to write the Carbon Plan, informed by a citizens' assembly to ensure public participation. 'Mini-public' deliberation on climate change has not taken place in Devon to date. Conducting research in advance of the Devon Climate Assembly, we use a risk analytical framework to investigate the per- ceived opportunities, drawbacks and uncertainties associated with the assembly by stakeholders and 'engaged' publics. We also attend to how perceptions of legitimacy and credibility play out across different geographies of urbanity and rurality, noting the lack of research on rurally based climate assemblies to date. We pose the following research questions:

RQ1: How do local stakeholders-specifically those commissioning the assembly and members of the wider public-perceive the opportunities and drawbacks of holding a Net Zero Citizens' Assembly in Devon?

RQ2: In terms of process and outcomes, what aspects of mini-public deliberation are considered crucial to its legitimacy and credibility?

Drawing on analysis of data from interviews with local stakeholders and from surveys with 'engaged' publics, the research addresses these research questions and contributes to debates concerning public trust in political institutions, and the institutionalisation and broader purposes of public deliberation (e.g., Dryzek et al., 2019; Farrell et al., 2019). The remainder of the article is structured as follows. In Section 2, we begin by setting out reasons behind the growing interest in deliberative public engagement on climate change, before discussing the benefits and challenges of mini publics such as citizens' assemblies (Section 2.1). We next show how our research builds on, and addresses gaps in the current literature (Section 2.2), before describing the context of our own study (Section 2.3). Section 3 sets out our methodology, and Section 4 outlines our key research findings. We discuss these findings more fully in Section 5 before presenting our conclusion.

\section{Public Deliberation and the Governance of Climate Change}

With many governments reluctant to divest from fossilfuels or risk reductions in economic growth, there has been a burgeoning interest at sub-national levels (e.g., cities and regions) in the role that mini-public deliberation might play in building a social mandate for action on climate change (Howarth et al., 2020). The interest in deliberative public engagement has also grown in the context of increasing disenchantment with 'formal' politics and elected politicians (Flinders \& Curry, 2008; Smith, 2009; Stoker, 2006), as well as political polarisation and the spread of misinformation (Farrell et al., 2019). Deliberation by mini-publics is contended to overcome many of the difficulties associated with political engagement through social media (Dryzek et al., 2019), notably an emphasis upon argumentative complexity, civility, listening, mutual respect and openness to persuasion. Given these developments, increasing interest at regional and local levels in applying public deliberation to 
the challenge of climate change is unsurprising. However, democratic innovation via mini-public deliberation on climate change at the local level also raises many challenging questions regarding risk and uncertainty in proposing, justifying and implementing mechanisms hitherto unfamiliar to local stakeholders and publics.

\subsection{Citizens' Assemblies as Mini-Public Deliberation}

Citizens' assemblies are a type of 'mini-public,' which involve bringing together a group of citizens-selected randomly to be representative of a wider populationto 'deliberate' on a specific topic on which they are provided with information (by experts, and other stakeholders) to inform a decision making process or public opinion (Dahl, 1989). They are just one variety of minipublic, amongst others such as citizens' juries, deliberative polls, consensus conferences and planning cells (Smith, 2009; Smith \& Setälä, 2018). These institutions bring together a random selection of citizens to deliberate on issues of public concern and to provide a collective recommendation, although the types of topics considered vary, as well as their size, and specific objectives. Citizens' assemblies have been described as "potentially the most radical and democratically robust" type of minipublic (Escobar \& Elstub, 2017, p. 3), partly because of their size, the length of time that can be involved compared to other mini-publics, i.e., usually over several weekends (Smith \& Setälä, 2018), the informed nature of the deliberations, and their potential for influencing public policy. Although citizens' assemblies are relatively rare, experimentation with their use is growing, and they have been utilised by national governments to garner public input into topics like electoral reform (the Netherlands, British Columbia, Ontario), abortion (Ireland), long term care (UK) and climate change (e.g., in France, UK and Ireland). There has been some, although more limited, use by local public authorities, for instance Vancouver's assembly on municipal planning (Beauvais, 2018), as well as by teams involving academics and civil society organisations on constitutional and multi-level governance issues (Flinders et al., 2016; Renwick et al., 2018). Thus citizens' assemblies are not novel, but their application to the challenge of climate change is a more recent phenomenon.

A central aspect of any mini-public is citizen deliberation involves "engaging with alternative arguments with an open mind" (Niemeyer, 2013, p. 435). Minipublics are part of a family of institutions designed to enhance citizen involvement in political decision making, sometimes described as 'democratic innovations.' Other democratic innovations include direction legislation, participatory budgeting and town hall meetings, and various forms of e-democracy (Smith, 2009). Mini-publics are used to complement rather than replace systems of representative democracy, and aim to improve the relations between citizens and decision-makers (Hendriks, 2006), and deepen citizenship, re-casting the role of citizens as co-producers and problem solvers (Elstub \& Escobar, 2019). They tend to be used in policy areas of high political salience, of constitutional importance, or which are politically sensitive or divisive, and are often employed to consider issues where decisions have to be made but where different policy options involve difficult trade-offs (Parkinson, 2004; Renwick et al., 2018).

One of the main benefits of citizens' assemblies, according to their advocates, is that their recommendations can command high public legitimacy (Elstub \& Escobar, 2019). Legitimacy claims stem from the rigour with which participants are selected, the informed nature of deliberations, the inclusion of expertise from credible and impartial witnesses, the variety of perspectives considered, and the richness of the debates. There is emphasis on creating institutional conditions that allow free and equal participation between citizens in a context of mutual respect and understanding (John, Smith, \& Stoker, 2009). From this perspective, incorporating elements of citizen deliberation into policy development can be said to enhance democratic legitimacy. However, the quality and legitimacy of citizens' assemblies themselves is contingent upon requirements including an open and transparent process, impartiality of witnesses, lack of interest group or political party dominance, and wider public engagement in the process (Devaney, Torney, Brereton, \& Coleman, 2020; Farrell et al., 2019). These can be regarded as issues of 'input legitimacy' which are focused around the participation and inclusion of relevant actors, and 'throughout legitimacy' concerned with the quality of processes and interactions involved (Devaney et al., 2020; Schmidt, 2013).

Despite the possible benefits of citizens' assemblies for addressing topics such as climate change, there are also limitations. These mechanisms only involve one small part of a population, albeit a statistically representative and randomly selected component. Participation is voluntary since those invited can decline the invitation, creating a potential self-selection bias (Smith \& Setälä, 2018). Those who do not take part (the majority of citizens) are left 'untouched' by the process (Parkinson, 2003). Lafont (2015) points out that the views of participating citizens are not representative of public opinion, since their opinions are likely to shift during the deliberation. She also questions the accountability of citizens' assemblies, as unelected bodies which other citizens may feel do not represent them. Others have noted that deliberative mini publics often lack real decision making power. Parkinson (2004, p. 385), discussing citizens' juries, notes that they sometimes make "recommendations that are within quite narrow boundaries that are determined by levels of power to which [the participants] do not have access." This underscores the importance of ensuring that where deliberative mini-publics are used, the agreed follow-up and implementation procedures following their recommendations are communicated clearly to participants, thus enhancing 'output legitimacy' (Devaney et al., 2020). 
Existing literature has not considered whether citizens' assemblies are perceived as a radical departure from politics as usual by the different groups involved in them, nor what these different groups consider to be their main purpose, risks and benefits. Research is lacking on whether social movements, the wider public and political/administrative actors hold different, and potentially competing, views about the purpose of citizens' assemblies on climate change, with the risk that the findings and recommendations of an assembly may be called into question and lack legitimacy. This is an important issue when local areas are experimenting with forms of democratic innovation and a key focus of this research.

\subsection{When a Local Area Engages with a Mini-Public for the First Time: Aspirations and Uncertainties}

Within the literature on citizens' assemblies specifically, there has been considerable emphasis on the experiences and views of participants themselves (Beauvais, 2018; Niemeyer, 2013; Renwick et al., 2018). Other research explores the views of the professional participation practitioners who conduct deliberative mini-publics (Cooper \& Smith, 2012). However, there is relatively little research on the views of either the public officers or political office holders who commission and organise citizens' assemblies, and even less examining wider public perceptions. Previous work has explored perceptions of these institutions among 'opinion leaders,' e.g., in a proposed citizens' climate assembly in Australia which did not come to pass, owing to opposition (Boswell, Niemeyer, \& Hendriks, 2013). Parkinson (2004) explored the motivations of health managers using citizens' juries, and found they were used as a means of testing out arguments. By bringing together witnesses, managers, professionals and lay people, the issues were thoroughly debated, giving clarity at the end of the process and a stronger sense of the legitimacy of competing arguments. Managers also viewed the juries as a means of rationalising polarised debates between competing interest groups, giving public managers the opportunity to make decisions that would be perceived as free of interest group domination. With regards to temporality, while much previous research focuses on experiences and reflections of participants during or after citizens' assemblies (e.g., Devine-Wright \& Cotton, 2017), less research has explored the period before the assembly has taken place.

The implication of these gaps is a lack of research upon the expectations and anticipations of democratic innovations when mini-publics such as citizens' assemblies are held in places for the first time. For political leaders, the decision to hold a mini-public climate deliberation is likely to require justification and legitimisation as to why a departure from 'business as usual' politics is required. Moreover, such innovation might be associated with considerable uncertainty and a range of potential risks and opportunities regarding what is involved, how it should be undertaken and what outcomes might arise. Accordingly, we apply a risk analytical framework (Pidgeon, Hood, Jones, Turner, \& Gibson, 1992; Slovic, 2010) to explore stakeholder and public perceptions of the Devon Climate Assembly, with a focus upon perceptions of its potential benefits and drawbacks for tackling climate change, as well as positive and negative affective responses. As part of this analysis we explore the extent to which a citizens' assembly is seen as a radical break and new way of doing climate politics, a mandate for more radical action, or whether there are other, more instrumental reasons for pursuing this type of deliberative mini-public, such as those alluded to above (Parkinson, 2004).

There are important spatial dimensions to democratic innovation. Local authority-led mini-publics on climate change, in the UK at least, have taken place in urban areas to date. Holding mini-public deliberations on climate change in rural areas is likely to raise particular challenges, not least in ensuring the representativeness of participants. Farrell et al. (2019) underscore the importance of random selection in the design of mini publics. Yet recruitment requires voluntary participation by citizens. Ensuring representative participation from scarcely populated or historically disadvantaged rural areas is likely to pose a challenge to the legitimacy of democratic innovation (Smith, 2009). Rurally facing climate assemblies also have to engage with a range of critical issues not faced by urban areas, notably the siting of large and controversial energy infrastructure such as wind turbines, provision of low carbon mobility to remote areas, and alterations to historical patterns of farming and land management.

\subsection{The Devon Carbon Plan and Climate Assembly}

Our research is conducted in Devon, the third largest County in the South West of England with a total population in 2019 of 1,2 million people and an average age of 43.7 years, above the national average (Devon Population Statistics, 2019). Rural areas account for $90 \%$ of Devon's land area, and the county is internationally recognised for landscapes of national importance; 35\% of Devon's land area is within Dartmoor and Exmoor National Parks together with five Areas of Outstanding Natural Beauty. Yet Devon also has major urban centres, three largest of which-Plymouth, Torbay and Exeteraccount for almost half of its population. There are significant wealth and life expectation gaps between areas in the north and south and between more remote rural and coastal populations that contrast to better-resourced urban and suburban based populations (Devon Health and Wellbeing Board, 2019). Recent government statistics highlight these income and lifestyle disparities with indices of multiple deprivation categorising parts of North Devon and Torridge as some of the most deprived places in England (Devon County Council, 2020).

In 2019, following Devon councils' declaration of a Climate Emergency, Devon County Council convened 
DCERG - a partnership to coordinate responses across Devon, with the aim of producing a Carbon Plan to reach net zero emissions. DCERG includes local councils and national parks $(n=14)$, health trusts $(n=3)$, private sector interests (e.g., utilities and farming organisations, $n=4)$, environmental organisations $(n=3)$ and academic institutions $(n=3)$. DCERG, in turn, set up a Devon Climate Emergency ('Net Zero') Task Force made up of 15 experts to write the Carbon Plan, and a Climate Impacts Group to create a regional Adaptation Plan.

DCERG devised a process to create the Carbon Plan that combined three steps. First, Expert Thematic Hearings were convened by the Task Force across November-December 2019, calling witnesses on Transport, Energy and Waste, Food, Land and Sea, Built Environment and Cross-cutting themes (Devon Climate Emergency [DCE], 2020a). Second, DCERG issued a Public Call for Evidence, with submissions reviewed by the Task Force for inclusion in the Carbon Plan. Third, DCERG committed to holding a Citizens' Assembly in order "to enable views of the general public to play an important role in the production of the Devon Carbon Plan" (DCE, 2020b).

DCERG and Devon County Council have collaborated with researchers from the University of Exeter to inform how the Devon Climate Assembly will be undertaken (see Positionality). University researchers were commissioned to conduct evidence reviews about citizens' assembly design and delivery, with the aim of ensuring adherence to best practice, and by association the legitimacy and credibility of the assembly. The Covid-19 pandemic severely disrupted the Carbon Plan process, pushing it back to mid-2021, necessitating the assembly to be held online. Instead of deliberating on the entire Plan, DCERG decided that the assembly would focus on a small number of particularly challenging and controversial issues. These include disincentives on private car use, changes to land management associated with reduced meat production and consumption, and use of onshore wind energy to generate low carbon electricity. Within this evolving local context, we address research gaps concerning the expectations and anticipations of democratic innovations when citizens' assemblies are held in places for the first time.

\section{Methodology}

A single case study research design (Yin, 1981) was employed, with the aim of providing an intensive, in-depth investigation (Sayer, 1992) of local stakeholder perceptions of the Devon Climate Assembly. Interviews with commissioning and independent expert stakeholders enabled deep insights into the perspectives of those commissioning the assembly process, with a specific focus on understanding the perceptions of local authorities and other local decision makers. A survey with engaged publics enabled us to gauge perceptions of public stakeholders who had declared an interest in the assembly process.
16 in-depth interviews were conducted between June and September 2020. Interviews were conducted with DCERG members from local authorities $(n=10)$, membership organisations such as land based, business and environmental organisations $(n=3)$ and a Devon County Council representative $(n=1)$ as well as members of the Devon Climate Emergency Task Force $(n=5)$. In the rest of the article when referring to DCERG stakeholders in general, we use the term 'commissioning stakeholders.' Elsewhere we use the term 'council stakeholders' to distinguish issues common to local authority interviewees. Interview questions focused on stakeholders' expectations of the Devon Climate Assembly and their perceptions of its value, challenges, risks, opportunities and uncertainties in the context of the wider Carbon Plan process (see the Supplementary File for interview schedule).

A questionnaire was used to capture the perceptions of engaged public stakeholders. Recruitment was undertaken in collaboration with Devon County Council, who identified and facilitated introductions to 100 individuals who had submitted evidence in the 2019 public consultation. Of the 31 people who completed the survey, only seven stated that they represented a voluntary organisation or activist group such as a local Green Party group and a Community Renewable Energy group. The majority (89\%) were aged 50 years or over. Geographically, public participants were more likely to reside in rural areas or the more populous areas of South and East Devon, with relatively few from urban areas. The survey questions focused on perceptions of, and confidence in, the public consultation process, expectations of the citizens' assembly, and perceptions of the risks and opportunities of using a citizens' assembly to address climate change (see the Supplementary File for survey instrument).

Interview data analysis was conducted using Nvivo led by the first author. Thematic analysis (Braun \& Clarke, 2006) was used to identify issues of risk and benefit, legitimacy and credibility that were important to participants, linked to the main research questions. Analysis of survey data combined descriptive analysis from multiple choice questions and manual thematic coding of open ended answers. Both sets of analyses were integrated to form an over-arching narrative using a form of triangulation (Baxter \& Eyles, 1997). In reporting the findings below, we use thematic headings which emerged as part of our predominantly inductive analytical approach.

In terms of positionality, this study was conducted in collaboration with Devon County Council-the lead instigator of DCERG-who co-designed and co-funded the research. Although acting as expert advisors within the process, through the production of two rapid evidence reviews on mini-public deliberation for DCERG and the Task Force, the researchers sought to maintain a selfreflexive position throughout when they engaged with the participating stakeholders, to retain a critical independence with regard to the aims of the research, methodology, and how the findings were interpreted and used. 


\section{Key Findings: Democratic Innovation, Climate Governance, Risk and Representation}

Our findings indicate that stakeholders across all groups believe that citizens' assemblies hold potential as sites of democratic innovation on climate change. However, a spectrum of opinions on the purpose of the Devon Climate Assembly were apparent, ranging from perceiving the need for innovative forms of democracy, to perceiving a need for intensive public education and behaviour change. Democratic innovation was perceived by all stakeholders as fraught with risk, albeit with distinct stakeholders being concerned about differing risks. These risks relate to the processes and outcomes of the assembly, focusing on issues of legitimacy, representation and the spatial context of the process. Commissioning stakeholders in particular made evident their fundamental concern to demonstrate that the assembly is a legitimate and transparent process.

This section will present the differing narratives of democratic innovation expressed via stakeholders' perspectives on the Devon Climate Assembly, whilst also interrogating perceptions around the risks of legitimacy, representativeness and the spatial context of the process.

\subsection{Democratic Innovation and the Challenge of Climate Emergency Governance}

For some council stakeholders, the value of the citizens' assembly was in "challenging the position of politicians...in order to make changes" (DCERG Interview June 2020). There was recognition that politicians and local authorities are unable to act alone to tackle climate change, resulting in a narrative of 'bringing the public on board.' Extending democracy to the people of Devon was seen as essential so that the public could "own it [the Carbon Plan] and feel that they can shape it. This is vital for a do-able, active plan" (DCERG Interview July 2020).

Stakeholders recognised that multiple complexities are inherent in the process of addressing pathways to Net Zero. For instance, they acknowledged the complexity of knowledge and information regarding climate change and the wide range of knowledges relating to different critical policy areas. In addition there was acknowledgment of the multiple scales of governance, notably the importance of central government for themes such as energy and transport, which further compound the context of making controversial policy decisions.

For council stakeholders, democratic innovation was viewed as creating a welcome pathway through these complexities, providing leadership and political cover for local authorities. A collective approach was welcomed within this narrative of 'hard decision making.' However ultimately interviewees feared that politicians may still make decisions with an eye toward winning elections. The Devon Climate Emergency Task Force interviewees focused on fears that the general public would reject an opportunity to make hard choices that would impact on their lifestyles and consumption practices. A smaller number of interviewees, representing membership bodies, feared that the citizens' assembly would produce outcomes that were too radical for their membership and/or are not implementable.

The citizens' assembly was, therefore, seen by stakeholders in multiple and overlapping ways-as a novel way to engage in climate policy making, and as an instrumental tool for public education, a theme expressed by a range of stakeholders who saw it as a process that "touches on people's lifestyles" and "instigates behaviour change" (DCERG Interview July 2020). Interviewees saw the potential for the assembly to enable policy and behaviour change, providing a sound evidence base for politicians and assembly members whilst also educating the wider public on why these issues matter and why hard decisions are required.

\subsection{Democratic Innovation and Risk}

There was awareness of great risk in implementing democratic innovation but also risk in remaining with politics as usual and not addressing the urgent issues of climate change. Mass climate change protests in 2019 were seen to have changed public perceptions of climate change and created a need for political action at all levels:

It was one of Extinction Rebellion's...national demands and we thought locally it made a lot of sense...there are things that we can do at a Devon level but there are things that need to be done at a national level....And there are things that can be done at a very local level that don't need any kind...of large organisational support for, and we wanted to try and find a way of expressing that. (DCERG Interview July 2020)

Our analysis highlights that commissioners of the Climate Assembly were aware of potential positive impacts of a citizens' assembly and wider Carbon Plan process. They emphasised the importance of a wider public engagement and a communication plan that would run alongside the citizens' assembly to enable the public to both follow the steps of the process, i.e., observe its legitimacy, and to be informed along with assembly members about the complexities of the issues under deliberation. However commissioning stakeholders were also highly aware of the risks of the assembly. Issues of legitimacy overarch the concerns commissioning stakeholder expressed about the assembly, which was seen to be of fundamental importance to the success of the project.

Engaged publics also expressed concerns regarding the legitimacy of the citizens' assembly process, with concerns about the procedures for running the assembly that focused on issues of representation, knowledge sharing and facilitation. Their concerns can be summarised as relating to issues of power and authority in decision making, i.e., whose voice and whose knowl- 
edge are listened to? "Legitimacy in my eyes would involve excellent leadership allowing full consideration of information \& proposals from bona fide scientists and climate experts....Who appoints the expert witnesses? Lack of transparency or bias in how people are invited to take part" (extracts from open ended questions from the engaged publics survey September 2020).

\subsection{Democratic Innovation and Representation}

Issues of representation were central to commissioning stakeholders' concerns and can be summarised as being primarily centred on achieving fair representation of Devon residents by taking into account perspectives from less populous, less economically resilient areas. This was seen as essential to achieve public buy-in for the outcomes of the Carbon Plan process. Secondly, issues of representation focused on bringing in wider perspectives into decision making, linking matters of representation with issues of power and authority in democratic innovation.

\subsubsection{The Rural Context to Climate Change Decision Making}

For council stakeholders, there were significant concerns how a public panel could represent the diversity of lived experiences across Devon. Concerns focused on those living in rural areas that experience a lack of services, less employment opportunities and areas of significant deprivation. There was concern that decisions taken in a citizens' assembly would not reflect the lived experiences of those living in less economically resilient rural localities. Council stakeholders projected anxiety that the more densely populated areas would attract more representation in the assembly process. They believed that city regions and densely populated areas would be prioritised in the recruitment process, side-lining and weakening rural voices:

I think you could be disenfranchising a large portion of...the Devon decision makers and...and the public as well, because it's not seen as being truly representative, and it's going to be the usual Exeter, Plymouth, Torbay focus....So it's not northern and it's not rural. (DCERG Council Interview June 2020)

Concerns about a lack of rural representation arose in part from where the 2019 expert hearings were held. Despite proposing several northern locations, hearings were conducted in the south and east of the county. Poor transport links and unreliable digital infrastructures were reasons, stakeholders believed, underpinning the decision not to hold hearings in North Devon. This fuelled concerns that spatial bias may be replicated in the representation of the Devon Climate Assembly itself.

Concerns relating to the lived experiences of rural areas were not limited to the operation of the assem- bly, but also linked to apprehensions about potential outcomes. Different types of stakeholders, including commissioning stakeholders and engaged publics, expressed concern that recommendations from the assembly relating to land use, the rural economy and farming may fail to account for the needs and heritage of rural and farming communities:

Devon has a real challenge in those rural areas having more reliance...on less sustainable travel or less sustainable energy...it's going to be very difficult for the carbon plan to come up with a one size fits all approach...not just the urban area...but the rural area.... where it's a bit more difficult...those areas could be left behind....So I think that taking the views of the rural areas on board... will help us to ensure more of a just transition across the whole county. (Devon Climate Emergency Task Force Interview July 2020)

This articulates awareness of the challenges of finding implementable climate outcomes that work across the varied geographies and lived experiences of Devon communities. Engaged publics also emphasised the importance of agriculture to the local economy of rural Devon; reinforcing stakeholders' agreement that representation of the rural voice on the assembly was imperative to perceptions of its effectiveness and legitimacy. That the Climate Assembly could unlock the complexity of devising climate change policies and strategies that are operable across the sub-region was a hope all stakeholders agreed with.

\subsubsection{Process of Participation: Bringing Wider Voices into Decision Making}

Public participation was viewed by commissioning and the Devon Climate Emergency Task Force stakeholders as an essential way of determining public perspectives on climate policy change, and as a method of generating public 'ownership' of those policy changes. The Climate Assembly was seen as a way to bring in wider perspectives to decision making, including usually disengaged voices. It was seen as a public engagement tool that would go beyond commonly used methods such as public consultations or information campaigns. For this reason and considering the inherent complexity of tackling climate change, stakeholders were predominately positive about the potential for the Climate Assembly to produce insights into public perspectives and as a vehicle to gain 'social permission from people' for policy outcomes (Devon Climate Emergency Task Force Interview September 2020):

You tend to get a certain demographic of people who respond...you don't really have an inkling of how representative it is of people who particularly don't tend to get involved. Particularly lower socio-economic groups, ethnic minority backgrounds, 
young people particularly. (DCERG Council Interview October 2020)

This reflects widely held views from stakeholders that question the legitimacy of conventional public engagement processes (and the demographic details of public respondents in our research partially supports this finding as the majority of respondents were aged over 50other demographic details such as education and ethnicity were not collected). The perception was that for more radical policy changes to be publicly acceptable, input from a more diverse demographic (that is perceived to be representative) is needed to ensure that policies that are approved will have the potential for wide public buy in. Citizens' assemblies were seen as making public engagement meaningful and having the potential to extend democracy to a wider demographic of citizens than those who usually vote.

Many stakeholders discussed the importance of having an extensive communication campaign running alongside the assembly. The objective of this would be to enable a Devon-wide audience to digest material shared to the assembly with the result that the public are educated about the imperatives and potential pathways for policy change. Some stakeholders offered suggestions for best practices for a successful communication campaign which focused on issues of who the public would listen to and engage with:

So the outcome of the citizens' assembly is presented in a language that will come across well on Spotlight [local area TV program], or Radio Devon...then ideally...there will be some leaders that emerge from the citizens' assembly...if they are people who the average viewer of Spotlight will relate to then that's going to be the way in which it's going to really land. (DCERG Council Interview July 2020)

Concerns about how to communicate to a wider audience to gain public buy-in on climate change policies links closely to wider themes of representation and questions relating to who has the authority to determine climate change policies.

Commissioning stakeholders expressed concerns about the impacts of Covid-19 on public perceptions of the urgency of climate action. Another impact of Covid-19 is the requirement to redesign public engagement to run online. Commissioning stakeholders perceived an online citizens' assembly to potentially overcome challenges of access, removing the necessity to transport assembly members and expert witnesses around the sub-region. However, all stakeholders expressed concern that a digital divide would impact on representation in an online assembly, which was seen as being a particular issue for rural and northern communities with poor access to digital infrastructures.

Taken together, the analysis indicates widespread support, yet also considerable risk and uncertainty asso- ciated with holding the assembly. Broadening the range of public voices inputting into policy was deemed necessary for effective climate response, although scepticism existed about the practical challenges of ensuring citizen representation, and about whether politicians, and society, would embrace the 'hard choices' required. Nonetheless there were aspirations that the assembly could serve as a tool for education and behaviour change, as well as providing a mandate for change. In summary, the research suggests an approach of 'cautious experimentation,' rather than a radical attempt to reconfigure power relations between citizens and politicians, with a commitment to democratic innovation widely embraced yet carefully constrained to minimise risk and uncertainty.

\section{Discussion and Conclusion}

Our research considers whether a 'new climate politics' is emerging across different societies, founded upon calls for urgent change from civil society groups and social movements, new narratives and declarations of Climate Emergency, the setting of target dates to achieve climate neutrality and the innovation of democratic mechanisms with an emphasis upon mini-public deliberation. Recent events in Devon, England present a suitable case study to begin to address this question of an emergent 'new climate politics,' given Emergency declarations by local councils, the establishment of a new stakeholder coalition and expert task force, and the commitment to hold a citizens' assembly on climate change. It also enables several research gaps to be addressed, notably concerning a priori risk perceptions held by stakeholders and non-participant publics concerning the benefits, drawbacks and uncertainties associated with a citizens' climate assembly, as well as important spatial dimensions of perceptions of legitimacy and credibility across rural and urban geographies. As such, the research contributes to debates concerning public trust in political institutions, and the institutionalisation and broader purposes of public deliberation (Devaney et al., 2020; Devine-Wright, 2017; Dryzek et al., 2019; Farrell et al., 2019). Such research knowledge also provides practical value to those wishing to embed deliberative public engagement alongside traditional representative democracy.

Addressing our first research question, we found that local stakeholders-specifically those commissioning the assembly and members of the wider publicperceived representative politics as unlikely to effectively tackle climate change due to its focus on time bounded, party political election cycles. A citizens' assembly and its wider governance processes, which entailed multiagency and multi-sectoral partnership of local organisations operating at different levels of governance, was seen as providing an opportunity to address the inherent complexity of climate change whilst also providing politicians with a process that would provide legiti- 
macy for the bold policy changes that might be required. As such, our research concurs with other work which has noted the role of deliberative mini-publics in tackling difficult and contentious issues (Parkinson, 2004; Renwick et al., 2018), and shows how the institutional apparatus surrounding an assembly can provide political decision makers and public managers with the legitimacy for decisions in these contentious areas. In terms of perceived risks and opportunities, the process of a citizens' assembly was seen as a tool for extending democratic processes beyond 'politics as usual,' engaging a wider set of voices than 'conventional' public participation processes. That said, there remained scepticism about the potential of an assembly to overcome political priorities connected to winning elections. A climate assembly was also viewed as an opportunity for public education and behavioural change, grounded in scepticism that publics would accept 'hard choices' embedded in everyday lifestyles and consumption habits. In this regard, the assembly can be seen, to some degree, as an instrumental tool to foster behavioural change, as much as the re-configuring of power relations between citizens and elected politicians (Elstub \& Escobar, 2019; Hendriks, 2006).

The assembly was also perceived by stakeholders as an opportunity to understand and involve diverse public perspectives, including those less likely to vote. From a policy maker's perspective, the assembly was seen as providing 'political cover' for local authorities to tackle complex controversies that have multiple scales of governance and geographies of citizens. Yet there was considerable uncertainty about the likely outcomes of an assembly, with some worried that its recommendations may be too radical, and others that they may not be radical enough. Worries were expressed that the outcomes and recommendations may disadvantage populations in the more rural and economically disadvantaged parts of the County, further contributing to longstanding geographies of social and economic vulnerability.

Addressing the second research question, concerns relating to legitimacy focused on diverse issues, bound up with the perceived necessity for inclusion of a wide range of perspectives including those from rural and farming areas, and the need for a process which was transparent and seen to be so, including transparency over the selection of witnesses. Taking account of the varied geographies of the county was seen as part of delivering a just transition to Net Zero. Process issues like good facilitation were mentioned as well as issues of design, formatting, quality of deliberation, what information is shared and by whom, the numbers of people involved, and how representative the assembly was perceived to be (issues of input and throughout legitimacy), as well as whether the findings were listened to and implemented, reinforcing the need for 'output legitimacy' (Devaney et al., 2020). Transparency and a robust process were therefore seen as critical to navigating the potential risks of the project.
Themes raised by research participants resonate with existing literature on democratic innovations. Key issues of representativeness/inclusiveness and transparency raised by our research are connected to the need for input and throughout legitimacy in citizens' assemblies articulated elsewhere (Devaney et al., 2020). Furthermore, mini-publics are conventionally seen as providing opportunities for engaging wider groups of participants than in other public engagement processes due to the processes of randomisation involved (Escobar \& Elstub, 2017; Smith, 2009; Smith \& Setälä, 2018). In our study concerns were expressed over whether this would be achieved, particularly in relation to the rural and less economically advantaged population, and digital divides that may emerge in an online assembly.

In conclusion, the case study provides an example of 'cautious experimentation' where a commitment to democratic innovation is widely embraced yet carefully constrained to minimise risk and uncertainty. Citizen input will be enabled by the assembly, but within a broader multi-stakeholder, multi-stage process where power remains vested in experts (in the Task Force) and incumbent institutions (in the DCERG) rather than youth, civil society groups or social movements. Moreover, the Devon Climate Assembly recommendations will only inform policy, not make decisions. In these ways, it can be said to offer a modest example of a 'new climate politics,' with minimal challenges, at least at this stage in the process, to the power and authority of existing institutions.

\section{Acknowledgments}

We would like to acknowledge grant funding from an ESRC Impact Acceleration Project Co-Creation Award (Grant Ref 113124R) and from Devon County Council on behalf of the Devon Climate Emergency partnership. We also thank our anonymous referees for their helpful comments and all our research participants.

\section{Conflict of Interests}

The authors declare no conflict of interests.

\section{Supplementary Material}

Supplementary material for this article is available online in the format provided by the author (unedited).

\section{References}

Baxter, J., \& Eyles, J. (1997). Evaluating qualitative research in social geography: Establishing 'rigour' in interview analysis. Transactions of the Institute of British Geographers, 22(4), 505-525.

Beauvais, E. (2018). The Grandview-Woodland Citizens' Assembly: An experiment in municipal planning. Canadian Public Administration, 61(3), 341-360. 
Boswell, J., Niemeyer, S., \& Hendriks, C. M. (2013). Julia Gillard's Citizens' Assembly proposal for Australia: A deliberative democratic analysis. Australian Journal of Political Science, 48(2), 164-178.

Braun, V., \& Clarke, V. (2006). Using thematic analysis in psychology. Qualitative Research in Psychology, 3(2), 77-101.

Bryant, P., \& Stone, L. (2020). Climate Assemblies and juries: A people powered response to the climate emergency. London: Shared Future and Place-Based Climate Action Network (PCAN).

Climate Emergency UK. (2021). List of councils who have declared a climate emergency. Climate Emergency UK. Retrieved from https://www.climateemergency. uk/blog/list-of-councils

Cooper, E., \& Smith, G. (2012). Organizing deliberation: The perspectives of professional participation practitioners in Britain and Germany. Journal of Public Deliberation, 8(1). https://doi.org/10.16997/jdd.125

Dahl, R. A. (1989). Democracy and its critics. London: Yale University Press.

Devaney, L., Torney, D., Brereton, P., \& Coleman, M. (2020). Ireland's Citizens' Assembly on climate change: Lessons for deliberative public engagement and communication. Environmental Communication, 14(2), 141-146.

Devine-Wright, P. (2017). Environment, democracy and participation. In D. Richardson \& N. Castree (Eds.), International encyclopaedia of geography (pp. 1-10). Hoboken, NJ: Wiley-Blackwell.

Devine-Wright, P., \& Cotton, M. (2017). Experiencing citizen deliberation over energy infrastructure siting: $A$ mixed method evaluative study. In S. Bouzarovski, M. J. Pasqualetti, \& V. Castán Broto (Eds.), The Routledge research companion to energy geographies (pp. 165-177). London: Routledge.

Devon Climate Emergency. (2020a). Thematic hearings. Devon Climate Emergency. Retrieved from https://www.devonclimateemergency.org.uk/ category/thematic-hearings

Devon Climate Emergency. (2020b). Devon citizens' assembly. Devon Climate Emergency. Retrieved from https://www.devonclimateemergency.org.uk/ devon-carbon-plan/citizens-assembly

Devon County Council. (2020). Social issues and deprivation. Devon County Council. Retrieved from https://www.devon.gov.uk/factsandfigures/socialissues-and-deprivation/deprivation

Devon Health and Wellbeing Board. (2019). Devon joint health and wellbeing strategy 2020-2025. Devon Health and Wellbeing Board. Retrieved from https:// www.devonhealthandwellbeing.org.uk/strategies

Devon Population Statistics. (2019). Devon population. Devon Population Statistics. Retrieved from https:// www.plumplot.co.uk/Devon-population.html

Dryzek, J. S., Bächtiger, A., Chambers, S., Cohen, J., Druckman, J. N., Felicetti, A., \& Warren, M. E. (2019). The crisis of democracy and the science of deliberation.
Science, 363(6432), 1144-1146.

Elstub, S., \& Escobar, O. (2019). Defining and typologising democratic innovations. In O. Escobar \& S. Elstub (Eds.), Handbook of democratic innovation and governance (pp. 11-31). Cheltenham: Edward Elgar Publishing.

Escobar, O., \& Elstub, S. (2017). Forms of mini-publics: An introduction to deliberative innovations in democratic practice. Sydney: newDemocracy Foundation.

Extinction Rebellion. (2019). The Extinction Rebellion guide to citizens' assemblies. Extinction Rebellion. Retrieved from https://extinctionrebellion.uk/wpcontent/uploads/2019/06/The-Extinction-RebellionGuide-to-Citizens-Assemblies-Version-1.1-25-June2019.pdf

Farrell, D., Curato, N., Dryzek, J. S., Geißel, B., Grönlund, K., Marien, S., . . . Setälä, M. (2019). Deliberative mini-publics: Core design features (Working Paper No. 2019/5). Canberra: Centre for Deliberative Democracy and Global Governance.

Flinders, M., \& Curry, D. (2008). Deliberative democracy, elite politics and electoral reform. Policy Studies, 29(4), 371-392.

Flinders, M., Ghose, K., Jennings, W., Molloty, E., Prosser, B., Renwick, A., ... Spada, P. (2016). Democracy matters: Lessons from the 2015 citizens' assemblies on English devolution. London: Electoral Reform Society.

Hendriks, C. M. (2006). Integrated deliberation: Reconciling civil society's dual role in deliberative democracy. Political Studies, 54(3), 486-508.

Howarth, C., Bryant, P., Corner, A., Fankhauser, S., Gouldson, A., Whitmarsh, L., \& Willis, R. (2020). Building a social mandate for climate action: Lessons from Covid-19. Environmental and Resource Economics, 76(4), 1107-1115.

Intergovernmental Panel on Climate Change. (2018). Global warming of $1.5^{\circ} \mathrm{C}$. summary for policymakers. IPCC. Retrieved from https://www.ipcc.ch/sr15/ chapter/spm

John, P., Smith, G., \& Stoker, G. (2009). Nudge nudge, think think: Two strategies for changing civic behaviour. The Political Quarterly, 80(3), 361-370.

Lafont, C. (2015). Deliberation, participation and democratic legitimacy: Should deliberative minipublics shape public policy? Journal of Political Philosophy, 23, 40-63.

Niemeyer, S. (2013). Democracy and climate change: What can deliberative democracy contribute? Australian Journal of Politics \& History, 59(3), 430-449.

Parkinson, J. (2003). Legitimacy problems in deliberative democracy. Political Studies, 51(1), 180-196.

Parkinson, J. (2004). Why deliberate? The encounter between deliberation and new public managers. Public Administration, 82, 377-395.

Pidgeon, N. F., Hood, C., Jones, D., Turner, B., \& Gibson, R. (1992). Risk: Analysis, perception and management: Report of a Royal Society study group. London: Royal Society. 
Renwick, A., Allan, S., Jennings, W., Mckee, R., Russell, M., \& Smith, G. (2018). What kind of Brexit do voters want? Lessons from the citizens' assembly on Brexit. The Political Quarterly, 89, 649-658.

Sayer, A. (1992). Problems of explanation and the aims of social science. In A. Sayer (Ed.), Method in social science (2nd ed., pp. 232-257). London: Routledge.

Schmidt, V. A. (2013). Democracy and legitimacy in the European union revisited: Input, output and 'throughput.' Political Studies, 61(1), 2-22.

Slovic, P. (2010). The feeling of risk: New perspectives on risk perception. London: Routledge.
Smith, G. (2009). Democratic innovations: Designing institutions for citizen participation. Cambridge: Cambridge University Press.

Smith, G., \& Setälä, M. (2018). Mini-publics and deliberative democracy. In A. Bächtiger, J. S. Dryzek, J. Mansbridge, \& M. Warren (Eds.), The Oxford handbook of deliberative democracy (pp. 1-19). Oxford: Oxford Handbooks Online.

Stoker, G. (2006). Why politics matters: Making democracy work. London: Palgrave Macmillan.

Yin, R. (1981). The case study as a serious research strategy. Knowledge, 3(1), 97-114.

\section{About the Authors}
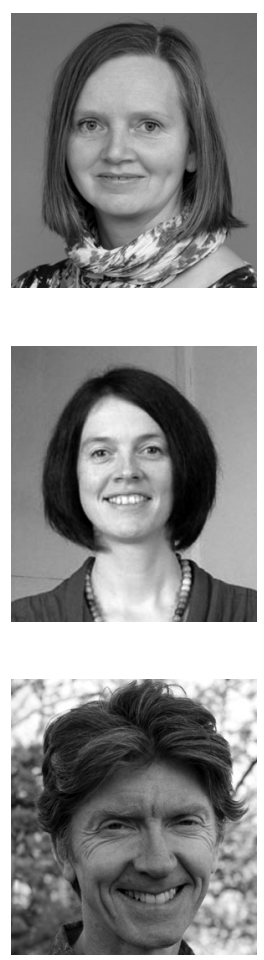

Rebecca Sandover is Lecturer in Geography at the University of Exeter. She is a Social Scientist with research interests in sustainable food networks, food policy partnerships and public participation in climate change policy making. Her recent work includes investigating action toward the formation of sustainable food networks in the South West UK, and stakeholders' perceptions of the Devon Climate Emergency's Net Zero Citizen Assembly.

Alice Moseley is Senior Lecturer in Politics, University of Exeter. She is a Political Scientist with research interests in civic participation, including deliberative engagement in public policy, and in behavioural public policy and administration. Her recent work connects these topics with issues relating to climate change mitigation and adaptation.

Patrick Devine-Wright is Professor of Geography at the University of Exeter. He is an Environmental Social Scientist with a primary interest in social acceptance of energy transitions, community engagement and place attachment. With expertise spanning human geography and environmental psychology, he was cited in the top 1\% of social science scholars globally by Web of Science in 2019 and 2020. $\mathrm{He}$ is an IPCC Lead Author on social aspects of climate change mitigation and Chair of the Devon Net Zero Task Force. 